\title{
A primeira escola de Serviço Social no cenário educacional brasileiro na contemporaneidade: breves notas
}

\section{The first School of Social Work in the Brazilian educational scenery nowadays: brief notes}

\section{Maria do Socorro Reis Cabral}

Mestre em Serviço Social, Departamento de Política Social e Gestão Social do Curso de Serviço Social da Pontifícia Universidade Católica de São Paulo/SP, Brasil.

helpcabral@hotmail.com

Inicialmente quero saudar aos meus parceiros de mesa, os assistentes sociais, docentes e alunos aqui presentes e agradecer à Cortez Editora pelo convite para partilhar desta mesa histórica de comemoração dos 80 anos do Serviço Social brasileiro.

Em meu depoimento destaco os desafios vivenciados na formação profissional em Serviço Social, nesta quadra histórica, referenciadas ao Curso de Serviço Social da PUC-SP, como primeira escola, fundada em 1936.
A segunda metade dos anos 1970 e 1980 até os umbrais da década de 1990 representou um período de grandes mobilizações e conquistas para o povo brasileiro. Nessa conjuntura, a universidade brasileira ingressa num dos períodos mais fecundos da sua história, com claros reflexos na PUC-SP, que firma uma concepção de universidade democrática, com compromisso social, formação de qualidade, assentada no tripé ensino, pesquisa e extensão e direção social comprometida com a produção do conhecimento e da pesquisa voltada para os interesses da maioria da população.

A conjuntura de lutas e mobilizações no Serviço Social deságuam na intenção de ruptura com o conservadorismo e na construção do Projeto Ético-Político, no Código de Ética de 1993, na Lei de Regulamentação da Profissão, também de 1993, e no Projeto de Formação Profissional assentado na referência da teoria social crítica.

A profissão completa 80 anos em uma quadra histórica demarcada por uma grave crise estrutural do capitalismo, em âmbito internacional, com crescente financeirização do capital, aprofundamento da distância entre os países capitalistas centrais e periféricos e acirramento das desigualdades, com reflexos no quadro brasileiro.

$\mathrm{O}$ aprofundamento da crise brasileira e o recente golpe jurídico-parlamentar-midiático, articulado pelas elites burguesas, anunciam suas primeiras medidas revela- 
doras de um grande retrocesso nos direitos sociais, historicamente conquistados. $\mathrm{Na}$ esfera trabalhista, encaminha-se a prevalência do negociado sobre o legislado; no âmbito dos direitos previdenciários, direciona-se para a liquidação de direitos e o privilégio da capitalização privada, convertendo a Previdência em instrumento de acumulação de capital; na saúde, o desmonte do SUS vai em direção ao proposto pela Organização Mundial da Saúde, em que a saúde pública se resumirá a uma cesta de procedimentos básicos. $\mathrm{O}$ bônus recai nos planos privados, portanto, em prol da saúde mercantil.

No cenário educacional, no que se refere à formação universitária, assistimos, no último período, como aponta Roberto Leher, reitor da Universidade Federal do Rio de Janeiro, à formação de grandes conglomerados a partir de megafusões, com clara inversão de valores, em que o primordial não é a educação em si, mas a busca exorbitante de lucros, por meio de fundos de investimento. Essas megafusões funcionam como verdadeiro holding, na medida em que articulam ao ensino as áreas de tecnologia informacional e editoração. Esses grupos têm se direcionado para a obtenção de lucros incessantes, via fundos de investimentos. O vertiginoso processo de financeirização e mercantilização da educação no país fica evidente.

Dados recentes apontados por Leher registram que cinco desses fundos de investimento abarcam $40 \%$ das matrículas universitárias e três deles detêm $60 \%$ das matrículas à distância.

Esses dados comprovam um vertiginoso processo de financeirização e mercantilização da educação no país.

No âmbito do ensino universitário público, o contingenciamento das receitas das áreas sociais põe o ensino público na vala comum da financeirização. As medidas do ajuste estrutural vão no sentido de restringir a ação do Estado no campo social e produtivo, transferindo empresas públicas para o setor privado e, sobretudo, alimentando o pagamento dos juros da dívida pública. Esse processo se realiza pela desvinculação das receitas da União (DRU). O cumprimento de metas fiscais no país tem significado uma economia de recursos para pagamento do serviço da dívida pública.

Ressalto, ainda, que a recomendação da Unesco para a educação protagoniza a elaboração de projetos educacionais de cariz tecnicista voltados para uma dimensão instrumental da formação profissional.

A PUC, como universidade privada, de caráter comunitário, tem enfrentado os desafios dessa conjuntura, adotando medidas em que o primado do financeiro se sobrepuja à política acadêmica, incidindo sobre as condições de trabalho docente e áreas de apoio. Como exemplo, tem-se a adoção do plano de demissões voluntárias, em 2006; demissões inconsistentes, maximização do trabalho docente, represamento de vagas na carreira docente, 
versões diferenciadas de plano de cargos e salários, restrição à pesquisa e à extensão, desrespeito às instâncias e descumprimento de orientações previstas nos projetos pedagógicos.

Quero aqui, publicamente, homenagear a profa. Marília Pardini, demitida à revelia do departamento e da então direção da faculdade, no quadro das demissões efetivadas pela universidade, em 2006, e que, após nove anos, teve garantido o seu retorno aos quadros do curso por força de uma sentença judicial. Devido ao quadro de sua saúde, encontra-se em licença médica. Marília, você sempre esteve presente entre nós. Nesse processo, fomos firmes e nos posicionamos com veemência contra as demissões.

O Curso de Serviço Social, como unidade de formação desta universidade, está sob os impactos dessa orientação, que marca a PUC-SP a partir de 2006. Contudo, não se transigiu na defesa do projeto pedagógico. O curso tem se caracterizado por um processo de resistência e de luta pela democratização da universidade, de modo a abrigar segmentos de trabalhadores.

Ao longo de sua trajetória de oitenta anos, o Serviço Social da PUC-SP realizou várias revisões curriculares, que passaram a ter caráter mais sistemático a partir de 1978, quando se definiu pela construção de um projeto experimental, cuja implantação deu-se no ano seguinte. A proposta curricular firmou a "necessidade do dire- cionamento da formação profissional prioritariamente para o conhecimento e ação junto às camadas populares", bem como a "necessidade de aprofundamento da análise da realidade institucional, campo de ação do assistente social (Yazbek, p. 34 apud Projeto Pedagógico do Curso, 1979).

Esse projeto experimental passou por um processo de análise avaliativa, nos anos 1980, e desaguou no currículo de 1982, como resultado do amplo processo de discussão que envolveu os agentes da formação e construiu uma proposta educacional consubstanciada em três dimensões básicas: docência teórico-prática, pesquisa e serviços. Essa formulação ocorreu em um momento peculiar de construção de um novo projeto educacional para a PUC-SP, em que a universidade se propôs a produzir conhecimento para os problemas e urgências da maioria da população. No plano conjuntural, temos a retomada das lutas populares e sindical no processo de redemocratização, inaugurando no país um novo patamar da luta de classes. Os assistentes sociais são partícipes desse processo de luta, tendo no III CBAS, em 1979, a sua referência mais emblemática de ruptura com o conservadorismo. No interior da formação e do exercício profissional dá-se um processo de renovação da profissão, que vai se expressar na intenção de ruptura e deságua, nos anos 1990, no Projeto Ético-Político profissional.

O projeto de revisão curricular do curso, de 1982, está afinado com as discussões 
que se travam na profissão e no interior da ABESS/ABEPSS e "assume uma das vertentes presentes no debate profissional, que, respaldada teoricamente e atenta à dinâmica do momento histórico, seja capaz de responder e superar a mera dinâmica oficial vigente no mercado de trabalho. Busca-se, pois, uma atuação profissional que reconhece as forças sociais hoje presentes no horizonte social dos interesses das classes subalternas" (Yazbek, p. 32 apud Projeto Pedagógico do Curso. In: Serviço Social \& Sociedade, São Paulo, ano V, n. 14, 1984).

Em 1996 implantamos as diretrizes curriculares, em obediência à proposta da Abepss, orientadora do projeto de formação profissional da categoria dos assistentes sociais, construída coletivamente. Sob uma conjuntura de dominância da ideologia neoliberal e de implantação de sua programática, significou a não garantia dos tópicos de estudo, quando da aprovação das diretrizes curriculares da área, pelo Conselho Nacional de Educação. Destaco que nosso projeto pedagógico se manteve centrado nas diretrizes curriculares definidas no interior da ABEPSS, e fomos o primeiro curso a implantá-la.

A revisão curricular de 2006, aprovada e implantada em 2010, se realiza num quadro de crise no interior da universidade, com inflexões na própria concepção de universidade, que se distancia da concepção construída pela comunidade acadêmica nos idos de 1980 e também vai se expressar no redesenho institucional, definindo um novo estatuto para a universidade, presidido pela lógica do caixa, com o enxugamento das estruturas acadêmico-administrativas. Esse momento também é demarcado pela redefinição do projeto pedagógico da universidade, agora sob a lógica que acentua o compromisso com a formação voltada para o mercado, em detrimento dos pressupostos de uma formação crítica, bem como construção da pesquisa e do conhecimento voltados para os interesses da maioria da população. Essa reforma administrativa vai reagrupar cursos e extinguir faculdades, com a vinculação de um só curso. Reagruparam-se cursos e faculdades, o que levou a integração da Faculdade de Serviço Social à Faculdade de Ciências Sociais, como estrutura de curso. Mais recentemente, a direção da universidade vem propondo a extinção dos departamentos.

A reforma curricular do Serviço Social empreendida no período em questão manteve-se fiel aos eixos do currículo de 1996, bem como aos parâmetros das diretrizes curriculares da ABEPSS, que se expressam na referência teórica do legado marxiano e da tradição marxista, na afirmação do Projeto Ético-Político. Trata-se, portanto, de compromisso com princípio fundamental do "reconhecimento da liberdade como valor ético central e das demandas políticas a ela inerentes - autonomia e plena expansão dos indivíduos sociais, e demais princípios firmados 
no Código de Ética (CFESS Código de Ética). O projeto tem, ainda, como eixos, a direção social da profissão e sua dimensão histórica; a afirmação da centralidade do trabalho, tomado na relação com a profissão; a afirmação da questão social como matéria-prima desse exercício, e como pressuposto básico, que deve perpassar o processo formativo na valorização da relação história/teoria/método.

Estou certa de que nosso projeto de formação, identificado com as diretrizes curriculares da ABEPSS e norteado pelo Projeto Ético-Político profissional, capacita o aluno a decifrar o real, a analisar os desafios postos à profissão e ao profissional, possibilitando-lhe construir respostas profissionais comprometidas com os setores populares, radicalizando na direção da garantia dos direitos sociais, sem perder a perspectiva estratégica da construção de uma ordem social que supere as desigualdades intrínsecas da sociedade do capital, na perspectiva de emancipação humana.

Por último, quero destacar um traço que vem se firmando na trajetória histórica do curso, que é o de se constituir num dos principais canais de democratização da PUC-SP, abrigando hoje um grande contingente de alunos trabalhadores, precarizados, terceirizados e sob forte ameaça de desemprego.

Nesse sentido, desenvolvemos um processo de luta pela redução na men- salidade do curso, conquistando um percentual de $25 \%$. Precisamos avançar na perspectiva da gratuidade e na construção de condições objetivas que contribuam para a efetiva permanência desse alunado para além do já conquistado.

O momento conjuntural brasileiro nos convoca à resistência e à retomada de mobilização contra a liquidação dos direitos historicamente conquistados e contra a onda conservadora que se instalou no país.

Obrigada!

\section{Recebido em 14/9/2016 \\ Aprovado em 10/10/2016}

\section{Referências bibliográficas}

YAZBEK, M. C. et al. (Orgs.). Serviço Social \& Sociedade, São Paulo, ano V, n. 14, 1984.

CONSELHO FEDERAL DE SERVIÇO SOCIAL (CFESS). Código de Ética dos Assistentes Sociais, Resolução CFESS, n. 273, de 13 de março de 1993. In: CONSELHO REGIONAL DE SERVIÇO SOCIAL DO ESTADO DE SÃO PAULO (Org.). Legislação brasileira para o Serviço Social. Coletânea de leis, decretos e regulamentos para instrumentalização da(o) assistente social. São Paulo: Conselho Regional de Serviço Social do Estado de São Paulo, 9ª Região, 2004. 